\title{
Control of Ionic Polymer Metal Composites
}

\author{
Robert C. Richardson, Martin C. Levesley, Michael D. Brown, Jamie A. Hawkes, Kevin Watterson, and \\ Peter G. Walker
}

\begin{abstract}
Robotic devices are traditionally actuated by hydraulic systems or electric motors. However, with the desire to make robotic systems more compact and versatile, new actuator technologies are required. In this paper, the control of ionic polymer metal composite actuators is investigated from a practical perspective. The actuator characteristics are examined though the unblocked maximum displacement and blocked force output. Open-loop position control then closed-loop position proportional, integral, and derivative (PID) control is then applied to a strip of actuators. Finally, the performance of the polymer is investigated when implementing an impedance controller (force/position control).
\end{abstract}

Index Terms-Actuator, EAP, force control, Ionic polymer metal composites (IPMCs), impedance control, , proportional, integral, and derivative (PID), position control.

\section{INTRODUCTION}

$\mathbf{C}$ ONVENTIONAL actuators such as electric motors, pneumatic cylinders, and hydraulic cylinders are traditional choices for robot actuation. Over the last decade, the development of new actuators has gained momentum resulting in several actuator technologies that may be suitable for robotic actuation. These alternative actuators include pneumatic muscle actuators (PMA) [1], piezo electric actuators [2], and electroactive polymers [3], [4]. Of these recent advances, electroactive polymers are the least developed with the first patent of electroactive polymers granted in 1993 [5]. A type of electroactive polymer called ionic polymer metal composite (IPMC) offers great potential due to its relatively large displacement, great force to weight ratio, and the ease at which it can be shaped and manipulated to form device specific actuators. Actuation is achieved under a low applied voltage $(<5 \mathrm{~V})$. Miniaturization of these actuators can be achieved by micro cutting of the material. Due to the early stage of development, these actuators are not commercially available. Fabrication of IPMC actuators requires the base Nafion polymer to be electrochemically plated to form an electrode pair [6].

Manuscript received August 1, 2002; revised January 20, 2003. This work was supported by the National Heart Research Fund, U.K. Recommended by Guest Editors C. Mavroidis, E. Papadopoulos, and N. Sarkar.

R. C. Richardson is with the Artificial Intelligence Group, Department of Computer Science, University of Manchester, Manchester M13 9PL, U.K. (e-mail: Rob@cs.man.ac.uk).

M. C. Levesley and P. G. Walker are with the School of Mechanical Engineering, University of Leeds, Leeds LS2 9JT, U.K. (e-mail: M.C.Levesley@leeds.ac.uk; P.G.Walker@leeds.ac.uk).

M. D. Brown is with the WS Atkins Consultants Ltd., Bristol BS32 4SD, U.K. (e-mail: MichaelD.Brown@atkinsglobal.com).

J. A. Hawkes is with the Department of Color Chemistry, University of Leeds, Leeds LS2 9JT, U.K. (e-mail: ccjah@leeds.ac.uk).

$\mathrm{K}$. Watterson is with the Yorkshire Heart Centre, Leeds General Infirmary, Leeds LS1 3EX, U.K.

Digital Object Identifier 10.1109/TMECH.2003.812835
TABLE I

NAFION PLATING PROCESS

\begin{tabular}{l|l}
\hline Stage & Reason \\
\hline $\begin{array}{l}\text { 1.Nafion surface } \\
\text { sand blasting }\end{array}$ & $\begin{array}{l}\text { Roughen polymer surface to ensure platinum } \\
\text { adheres to polymer surface }\end{array}$ \\
\hline $\begin{array}{l}\text { 2. Primary } \\
\text { plating }\end{array}$ & $\begin{array}{l}\text { Electrochemically deposit a thin layer of } \\
\text { platinum on the Nafion surface }\end{array}$ \\
\hline $\begin{array}{l}\text { 3.Secondary } \\
\text { plating }\end{array}$ & $\begin{array}{l}\text { Deposit a thicker layer of platinum on top of } \\
\text { the primary plating }\end{array}$ \\
\hline
\end{tabular}

Research is ongoing to improve the performance of these actuators by methods such as increasing the thickness of the polymer [7] and an additional coating of metal [8], [9] however, at their present state of development, these actuators exhibit excellent power to weight ratio combined with large relative displacement. Research has proven the response of IPMC actuators difficult to model [10]-[12], and few control strategies have been applied to IPMC actuators [13], [14].

Here, control of the actuators is investigated by considering the open-loop-position control response and comparing it to the closed-loop PID response. For modern robotic applications position control is no longer sufficient. A form of force/position control, termed impedance control, has been applied to the actuator to demonstrate its performance.

Section II provides an overview of IPMC actuators. Section III assesses the actuator characteristics. Section IV applies the three different control strategies to the actuator and discusses the results. Finally, the conclusions of the study are presented in Section V.

\section{OVERVIEW}

IPMCs are currently not commercially available because they require on-site fabrication. The fabrication process is described in [6]. During the fabrication process, sheets of Nafion polymer are electrochemically plated with platinum to form sheets of IPMC. The major steps in this plating process are outlined in Table I, however, the interested reader should note hazardous chemicals are used in the plating process. Fig. 1 shows the finished IPMC actuator sheet. This sheet can then be cut into the required shape using a knife. Note that the thickness of the actuator is approximately $0.2 \mathrm{~mm}$.

The actuation mechanism of IPMC actuators is not yet fully understood. However, the basic mechanism is known [10], [11]. When voltages are applied to the platinum electrodes at either side of the polymer surface an electric field is applied across the membrane. Sodium ions migrate from the anode to the cathode due to electrostatic force. When the polymer is hydrated, water travels with these ions, causing contraction on one side of the 


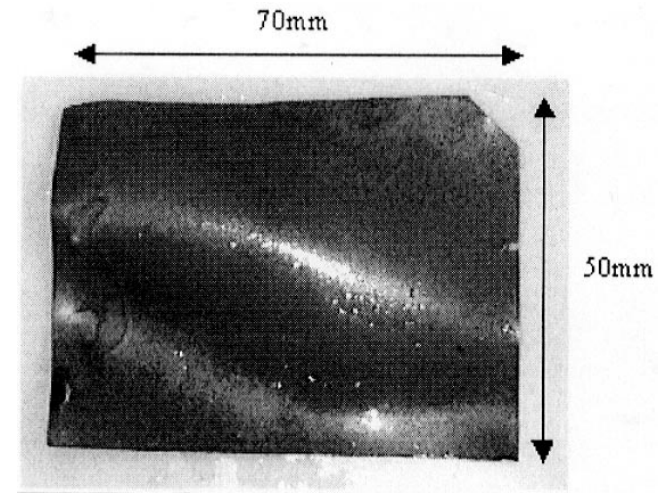

Fig. 1. Sheet of IPMC actuator.

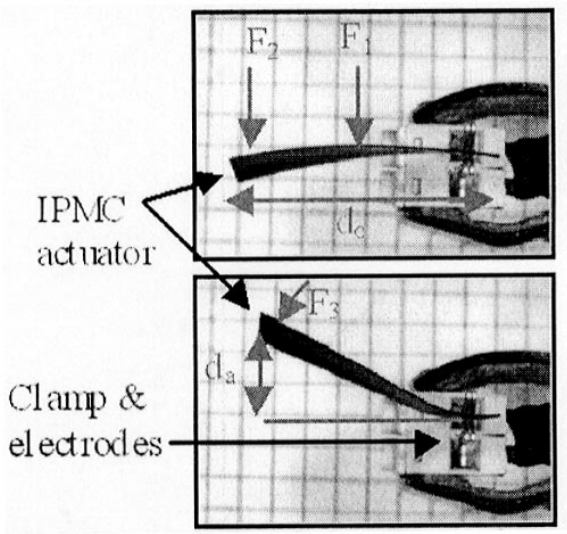

$0 \mathrm{~V}$

Fig. 2. Response on a strip of IPMC.

membrane and expansion on the other. Hence, the membrane bends. Under the dc electric field, the material strain is not maintained with the actuator eventually returning to its original state. The bending motion is illustrated in Fig. 2. Bending occurs across the whole length of the IPMC. However, due to the surface resistance of the platinum and the properties of the membrane, the greatest electric field and bending is close to the clamp. The IPMC actuator performance is subject to the amount of hydration and material history [15].

To illustrate the versatility of the actuator technology, a simple gripper has been created based on an idea by [16] (Fig. 3). Three strips of IPMC are arranged in a circle. When a voltage is applied, the polymers bend and grasp the object. It is interesting to compare the simplicity of this arrangement to that of a similar device actuated by electric motors or hydraulic/pneumatic systems. To use conventional actuators would require significant mechanical design with gears or levers, increasing the system complexity.

\section{ACTUATOR PROPERTIES}

To evaluate the performance of the actuator, a test rig was developed to test both position and force characteristics (Fig. 4). The IPMC is clamped between two electrodes that enable varying voltage to be applied to the platinum electrodes of the IPMC. When voltage is applied, the IPMC will bend with the laser position sensor measuring the resulting displacement. Note that the actual bending motion of the actuator follows a

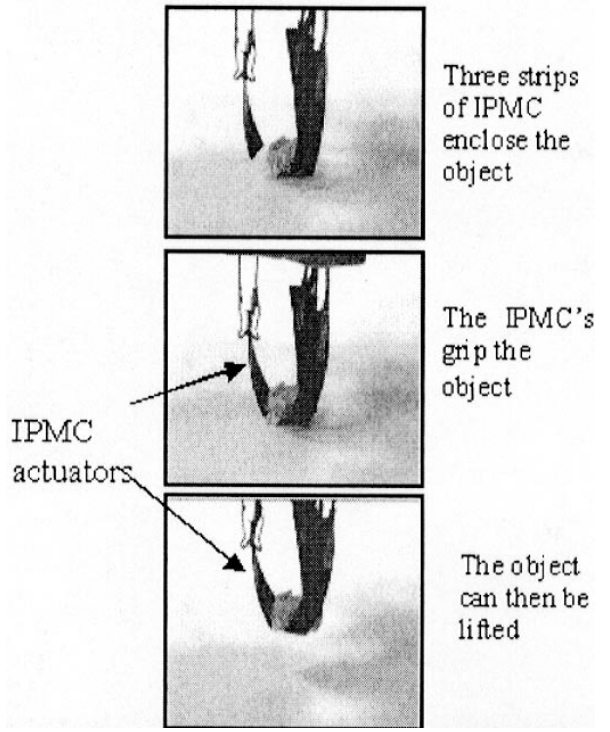

Fig. 3. Simple three-fingered gripper.

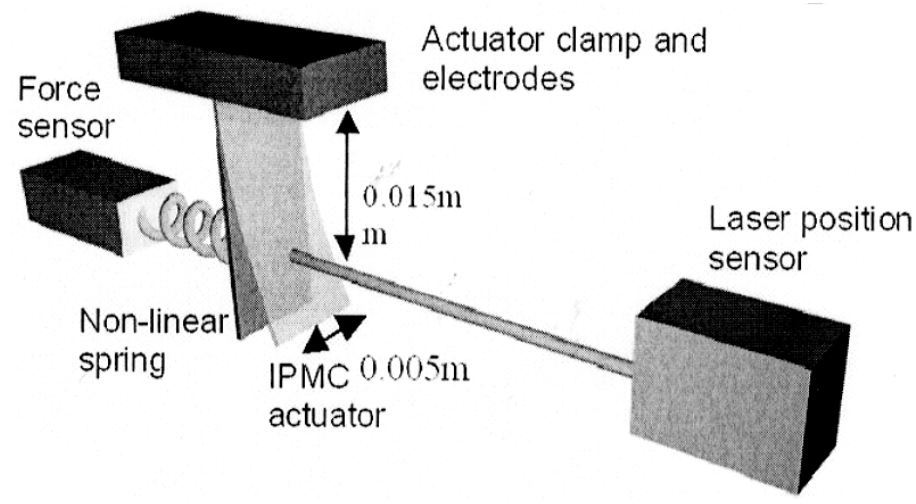

Fig. 4. Experimental equipment.

curvature [17]. If the displacement is small, then the end-point motion can be measured using a laser position sensor. A force sensor measures the applied forces. This force is measured through a spring when implementing impedance control.

At the current stage of development, IPMCs are required to be hydrated as water is a major part of the actuation process. However, rubber coatings are being developed to restrict the water from evaporating [18], increasing the life of the actuator out of water to more than three months. Also, alternatives to water are under consideration for the actuation mechanism that do not evaporate [19]. In this instance, tests were performed by fully hydrating the polymer and then attaching it to the electrodes. After each test, the actuator was soaked in water again. The voltages applied to produce actuation are low, less than $5 \mathrm{~V}$. However, if voltages above $1.23 \mathrm{~V}$ are applied, electrolysis will occur, resulting in loss of water and hydrogen gas being produced. As a result, many researchers limit the applied voltage to less than $1.23 \mathrm{~V}$, thus greatly reducing the actuator motion. In this instance, voltages $<5 \mathrm{~V}$ are applied to achieve the required response.

The IPMC actuator was manufactured on site and as such its properties differ slightly from IPMC produced by other researchers. The important parameters to ascertain are the force 


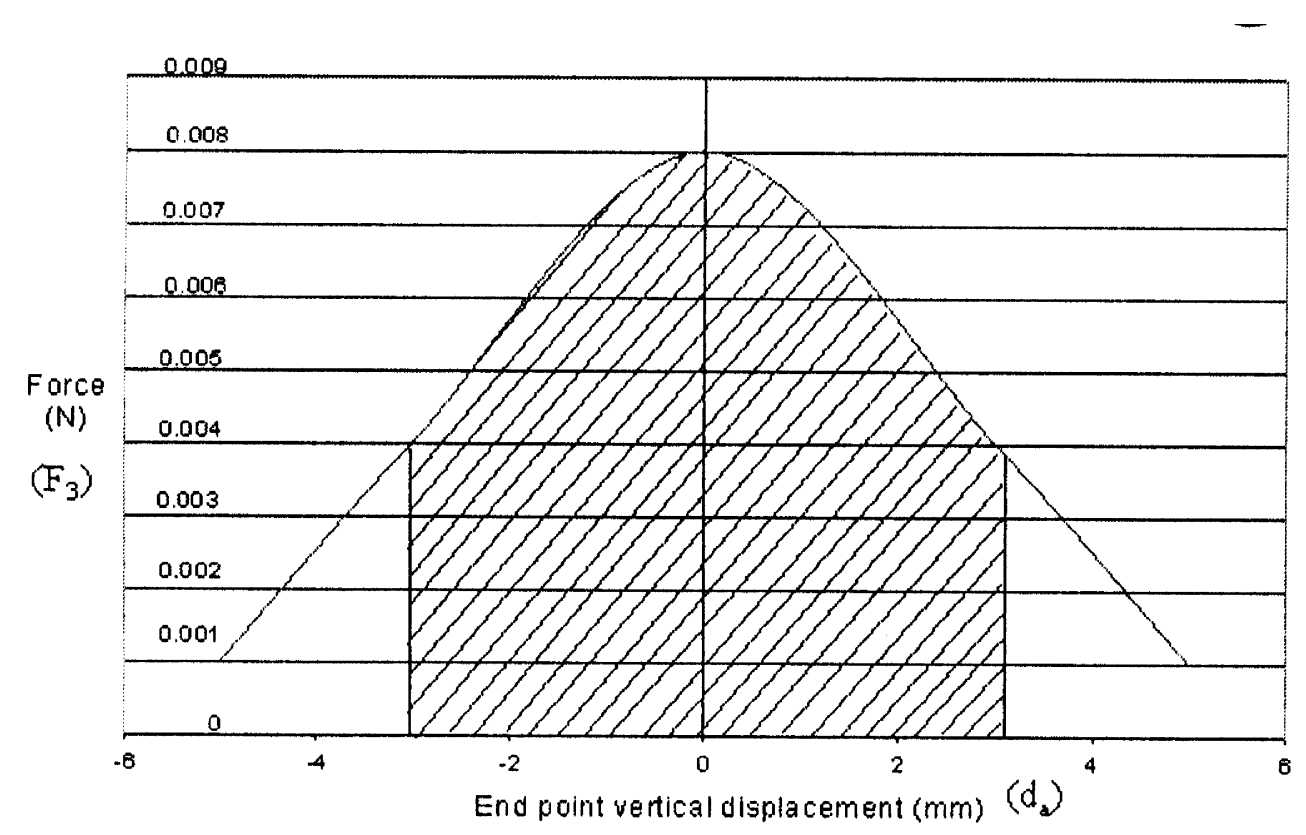

Fig. 5. Force output during bending motion of IPMC.

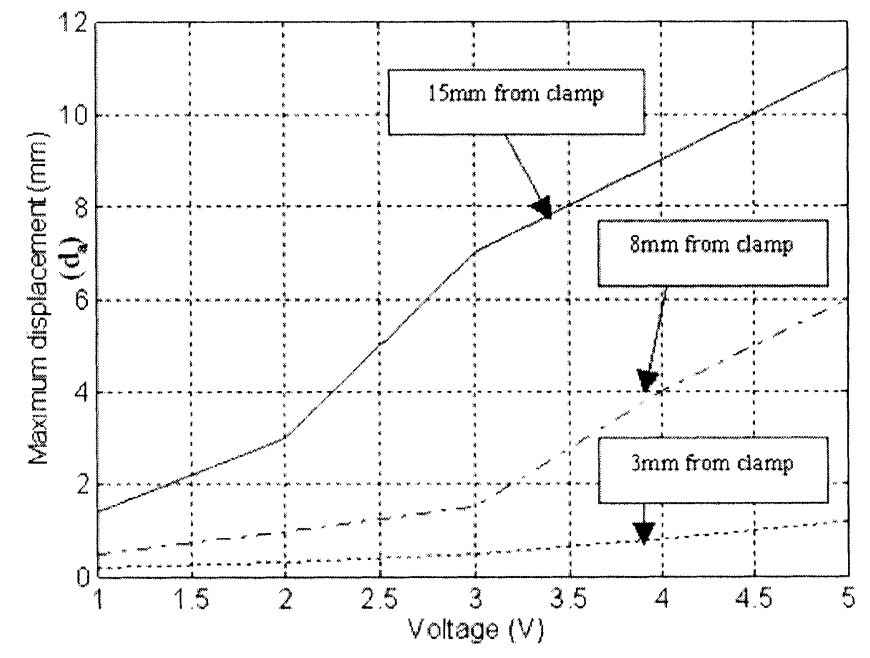

Fig. 6. Maximum displacement at different lengths of IPMC actuator.

output and displacement. The blocked force output of the actuator varies nonlinearly with distance from the clamp, primarily due to leverage effects but also due to electrical resistance of the thin platinum coating (i.e., $F_{1}$ in Fig. 3 is closer than $F_{2}$ to the clamp and is therefore larger).

As the IPMC bends under applied voltage, the force output also decreases as the IPMC acts against its own inherent elasticity [i.e., in Fig. 3 the blocked force $F_{3}$ is less than $F_{2}$ even though the distance from the clamp $\left(d_{c}\right)$ is the same]. The force/displacement graph when $3 \mathrm{~V}$ of voltage is applied is shown in Fig. 5. It is important to note that the actuator force output reduces to being very small at the limits of motion. If the actuator is to apply force at the defined extremities of motion, its operational range must be limited. In this instance, the suggested operational range is the hatched region of Fig. 5. The maximum displacement (unblocked) has been characterized at various distances from the clamp and input voltages (Fig. 6).
The largest displacement is achieved for the greatest voltage and distance from the clamp.

\section{CONTROL}

In this section, control of the actuator is investigated through open-loop position control, PID position control, and impedance control applied to the strip of IPMC.

\section{A. Open-Loop Position Control}

The simplest form of control is open-loop control. Due to the structure of the material, open-loop voltages cause movement of the IPMC until the elastic resistance in the material itself balances the force generated by the voltages.

When performing open-loop control, a voltage step response is applied across the electrodes. The magnitude of this step input has been empirically adjusted to give a steady-state response of approximately $2 \mathrm{~mm}$. The applied voltage cannot be too great as the actuator steady-state position would exceed that of what was desired. The open-loop controller has approximately the correct steady-state gain and a slow rise time (Fig. 7).

\section{B. Closed-Loop Position Control}

The response obtained through open-loop control is limited with the speed of the response dictated by the final settling position. Closed-loop control enables larger voltages to be applied to the polymer during the transient stages of the response. PID control is an industry standard control technique due to its performance and the ease at which it can be implemented. To implement the position controller, a laser position sensor provides closed-loop feedback (Fig. 4). A PID controller has been applied to the IPMC actuator with the gains obtained using the ultimate gain method [20]. The closed-loop response (Fig. 8) is superior to the open-loop response with a quick response time and small steady-state error. The integral element in PID control is capable 

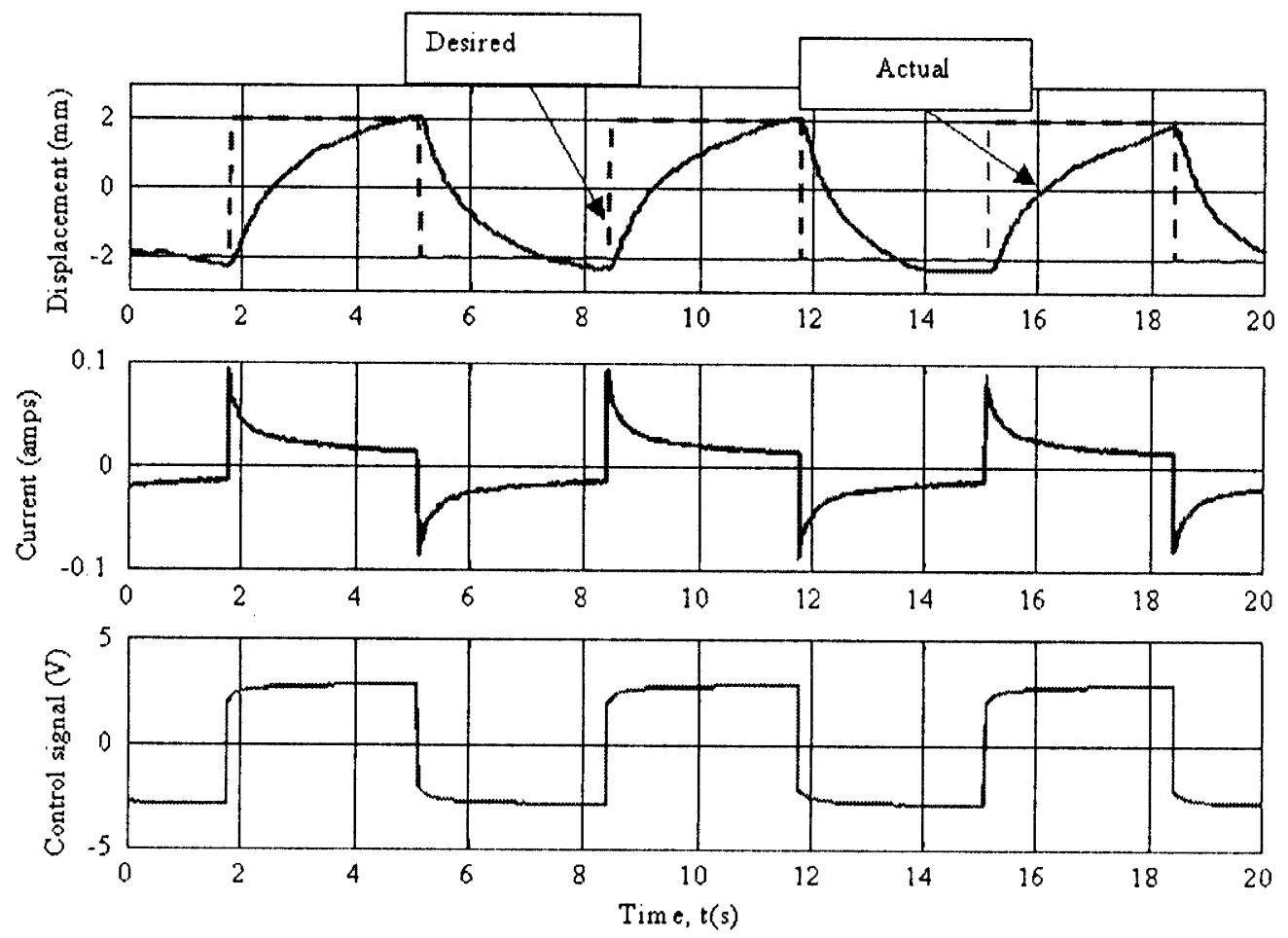

Fig. 7. Open-loop response.
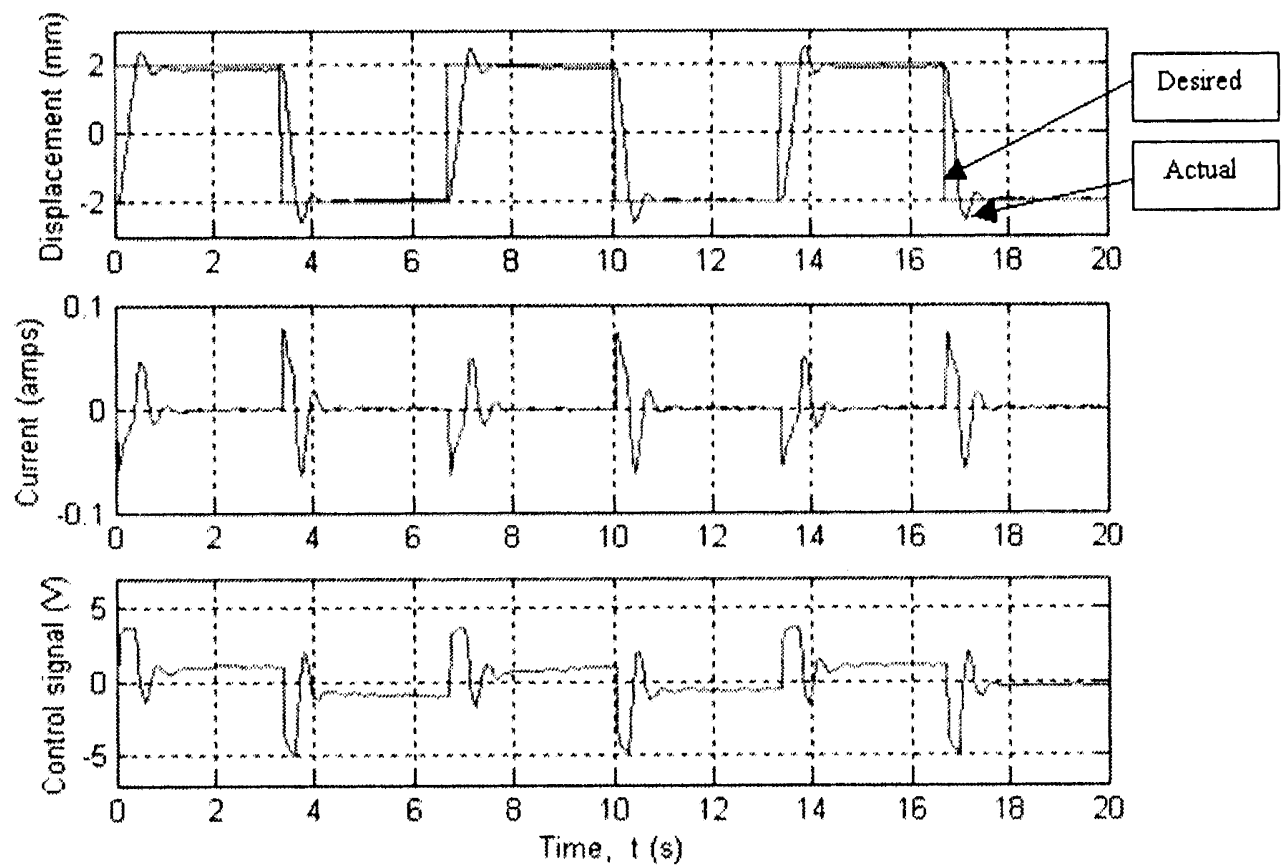

Fig. 8. Closed-loop position control.

of slowing the material relaxation when a constant (dc) position is required by gradually increasing the applied voltage.

\section{Impedance Control}

Impedance control has been developed over the last decade to enable robots to perform adequately when no exact model of their operating environment is known, and hence, purely position control or force control is not possible [21]. Examining how humans interact with their environment was an integral part of this controller's development. Impedance control does not control the position or force, but rather the dynamic relationship between the two.

1) Theory: Impedance control utilizes a mass, spring, and damper relationship between force and position (Fig. 9). The 


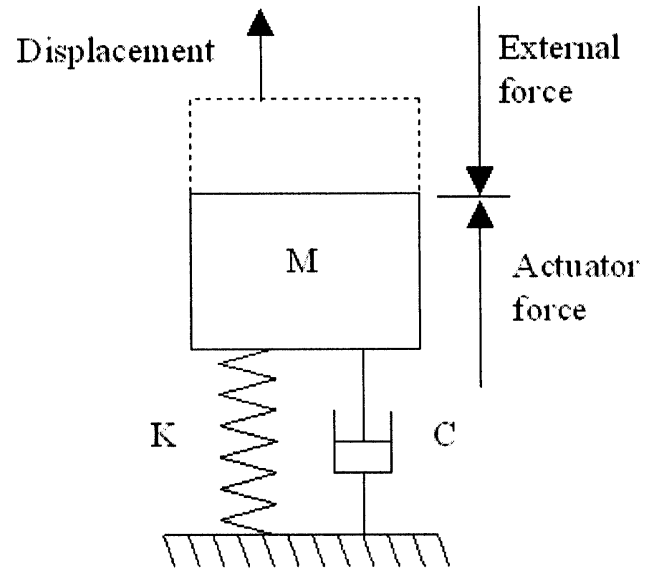

Fig. 9. Impedance control free-body diagram.

TABLE II

Evaluation of ImPEDANCE CONTROL AND AdMITTANCE CONTROL STRATEGIES

\begin{tabular}{l|l|l}
\hline & $\begin{array}{l}\text { Admittance control } \\
\text { (position based) }\end{array}$ & \multicolumn{1}{c}{$\begin{array}{c}\text { Impedance control } \\
\text { (Force based) }\end{array}$} \\
\hline $\begin{array}{l}\text { Most appropriate for } \\
\text { environments } \\
\text { consisting of stiffness } \\
\text { and damping } \\
\text { elements. }\end{array}$ & $\begin{array}{l}\text { Most appropriate for } \\
\text { environments consisting } \\
\text { of inertial elements. }\end{array}$ \\
$\begin{array}{l}\text { Only requires addition } \\
\text { of a force sensor on } \\
\text { conventional robotic } \\
\text { devices based around } \\
\text { measurement of link } \\
\text { position. }\end{array}$ & $\begin{array}{l}\text { Easy to implement on } \\
\text { direct-drive electric } \\
\text { motor systems due to } \\
\text { the ease at which torque } \\
\text { can be controlled during } \\
\text { motion. }\end{array}$ \\
\hline $\begin{array}{l}\text { Requires a high gain } \\
\text { position controller } \\
\text { robust to external } \\
\text { force disturbances } \\
\text { advantages }\end{array}$ & $\begin{array}{l}\text { Difficult to implement } \\
\text { on actuator systems } \\
\text { where force output is } \\
\text { effected by robot } \\
\text { movement. }\end{array}$ \\
& & $\begin{array}{l}\text { Requires robot inertial } \\
\text { model, which can be } \\
\text { difficult to obtain. }\end{array}$ \\
\hline
\end{tabular}

transfer function connecting force and position, considering position as an input and force as an output, can be specified in the $s$ domain as

$$
\frac{F_{x}}{x_{i}}=M s^{2}+C s+K
$$

where $x_{i}$ is the change in position due to external force $\left(F_{x}\right), M$ is the inertial component, $C$ is the damping component, and $K$ is the stiffness component. Rearranging (1) so that force becomes the input and position the output, results in

$$
\frac{x_{i}}{F_{x}}=\frac{1}{M s^{2}+C s+K} .
$$

A controller formed from (2) is known as admittance control or position-based impedance control. Equations (1) and (2) are known as the duality of impedance control. These two subtly different approaches require different controller structures. A more detailed discussion of these differences can be found in
[22], but a summary of the advantages and disadvantages of each type of impedance controller is given in Table II. As highlighted by [23], position-based impedance control (admittance control) is suitable for actuators with nonlinear characteristics. Note that full implementation of impedance control includes an inertial element so that robots can mimic the physical properties of objects for applications such as haptic interfaces [24]. For movement purposes, the inertial element is not used with the controller required to mask the physical inertia of links and joints.

2) Controller Structure: Fig. 10 illustrates the impedance controller structure. The heart of the controller is a PID position controller, which controls the position as previously. However, unpredictable external forces are now applied to the actuator. The measured external forces feedback through an impedance filter to modify the desired position in a predictable manner depending upon the specified mass, spring, and damping parameters. Assuming small displacements, the actuator is considered to move in a linear way enabling a standard spring and damping model to be used, as in Fig. 9. For larger displacements, a more complex beam stiffness and damping model would be required. In the experimental system, a force sensor and spring apply and measure external forces applied to the IPMC (Fig. 4).

The force sensor measures the forces applied to the IPMC through the spring. Ideally, the actuator would have force sensors mounted upon it so that it could interact freely with any environment. Due to size limitations and the IPMC low-force output, the force sensor has been mounted externally. When the IPMC moves into contact with the spring, a force is exerted upon it with the specified impedance characteristics determining whether the IPMC moves the spring or whether the spring restricts IPMC motion.

3) Results: The results of the impedance controller implementation are detailed in this section. It is important to note there are now three position traces: the virtual position, desired position, and actual position. The virtual position is the initial demand position specified before commencement of motion. The desired position includes the effect of external forces acting through an ideal spring and damper system. The actual response is the actual IPMC position as measured by the laser sensor. Note that if the controller behaved ideally, the actual and desired would be identical. Results were obtained for a selection of damping and stiffness parameters.

The first response implemented a damping coefficient of $0.1 \mathrm{~N} / \mathrm{ms}^{-1}$ and a stiffness of $50 \mathrm{~N} / \mathrm{m}$. As a result of the relatively high stiffness, the virtual position and the desired position are almost identical (i.e., the external forces encountered are too small to noticeably compress the impedance filter spring and damping arrangement). This requires the IPMC to exert sufficient force to move through the spring. Fig. 11 is the IPMC response with the above-mentioned damping and stiffness parameters. After $15 \mathrm{~s}$, the spring and force sensor are placed in the line of motion of the IPMC. The response of the IPMC is slower, and there is an increased potential difference applied across the polymer to produce the additional force to act against the spring. However, the IPMC achieved the desired steady-state position. Decreasing the stiffness of the impedance controller causes external forces to have a greater influence. 


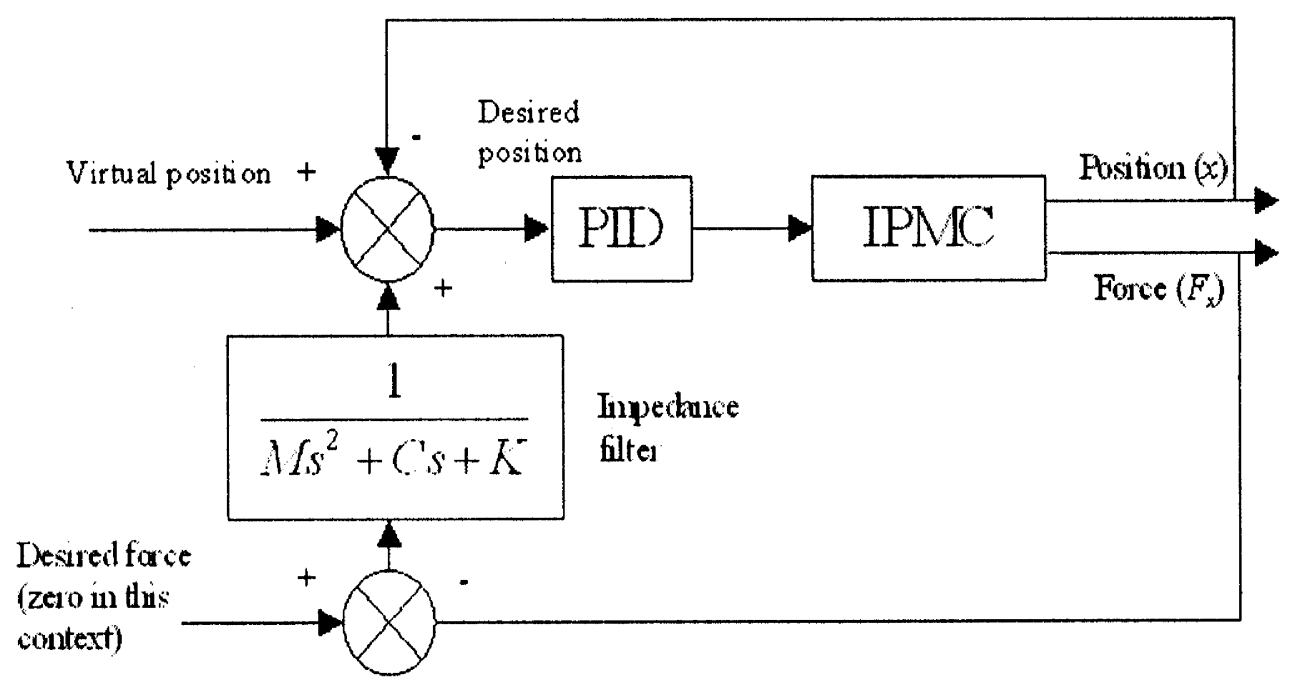

Fig. 10. Impedance controller structure.
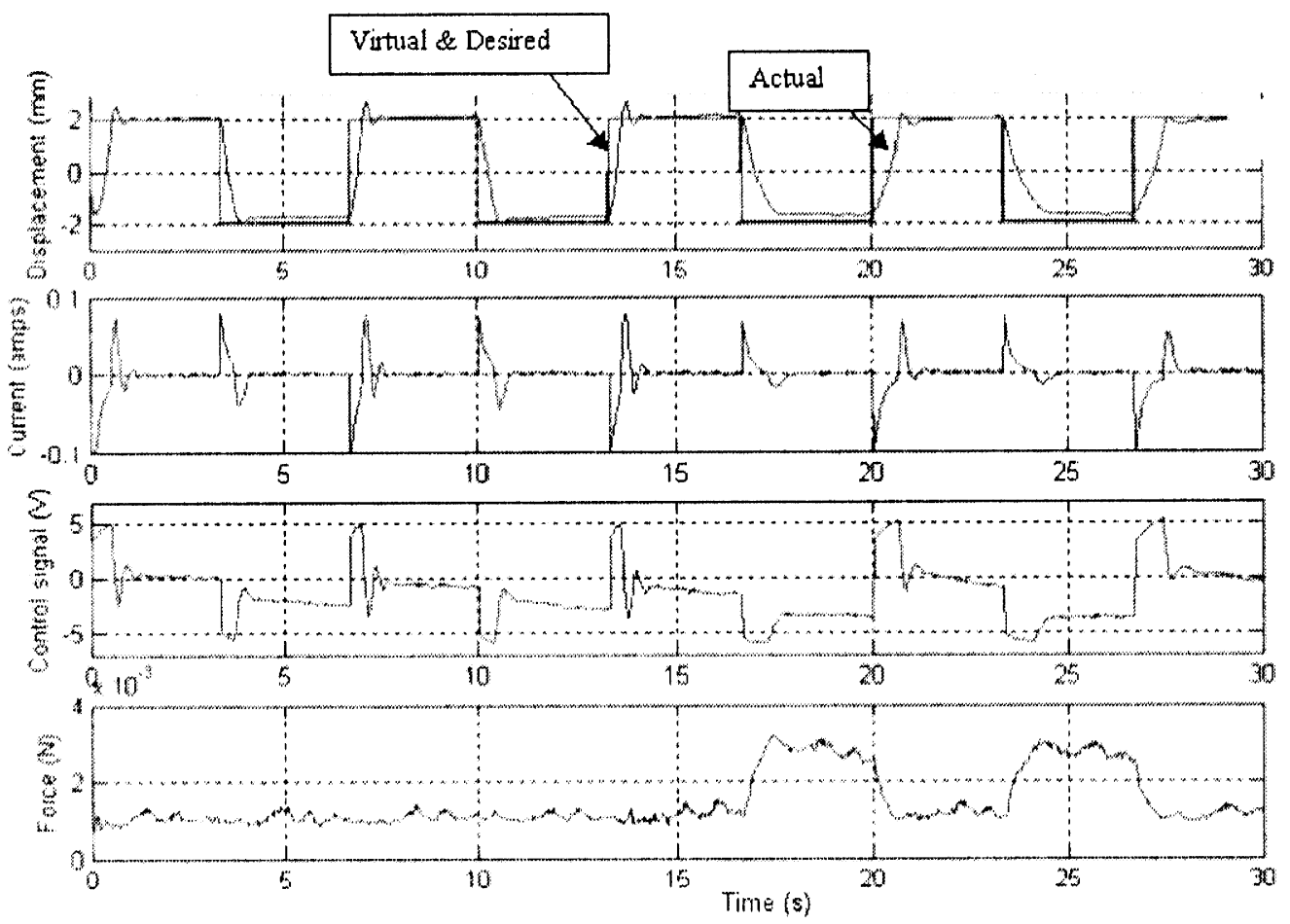

Fig. 11. IPMC impedance response $\left(K=50 \mathrm{~N} / \mathrm{m}, C=0.1 \mathrm{~N} / \mathrm{ms}^{-1}\right)$.

The controller response $\left(K=1 \mathrm{~N} / \mathrm{m} C=0.1 \mathrm{~N} / \mathrm{ms}^{-1}\right)$ is shown in Fig. 12. The external force causes the desired position to change significantly. Note that the spikes in the desired position are caused by the delay in actuator response. The desired position is tracked. However, there are delays in response.

Finally, the spring is brought into permanent contact with the actuator (Fig. 13). In spite of the presence of external forces, the actuator still moves, with the IPMC movement effected in a predictable manner. The output voltage approaches saturation when these forces are applied.

The PID controller behaves well and offers some robustness to external forces (i.e., the IPMC actuator almost follows the desired trajectory inspite of the external forces). It is possible to include a feedforward force element to reduce some of the burden on the position controller due to these external forces [25]. However, an approximate model of the actuator force output response would be required.

\section{CONCLuSions}

The control of IPMCs has been discussed and also demonstrated by experimental implementation. In its current form, the IPMC actuator would have limited practical applications due to the small force output obtainable. However, it has been demonstrated that force and position controllers can be effectively implemented on the polymer actuator. To rigorously analyze the 

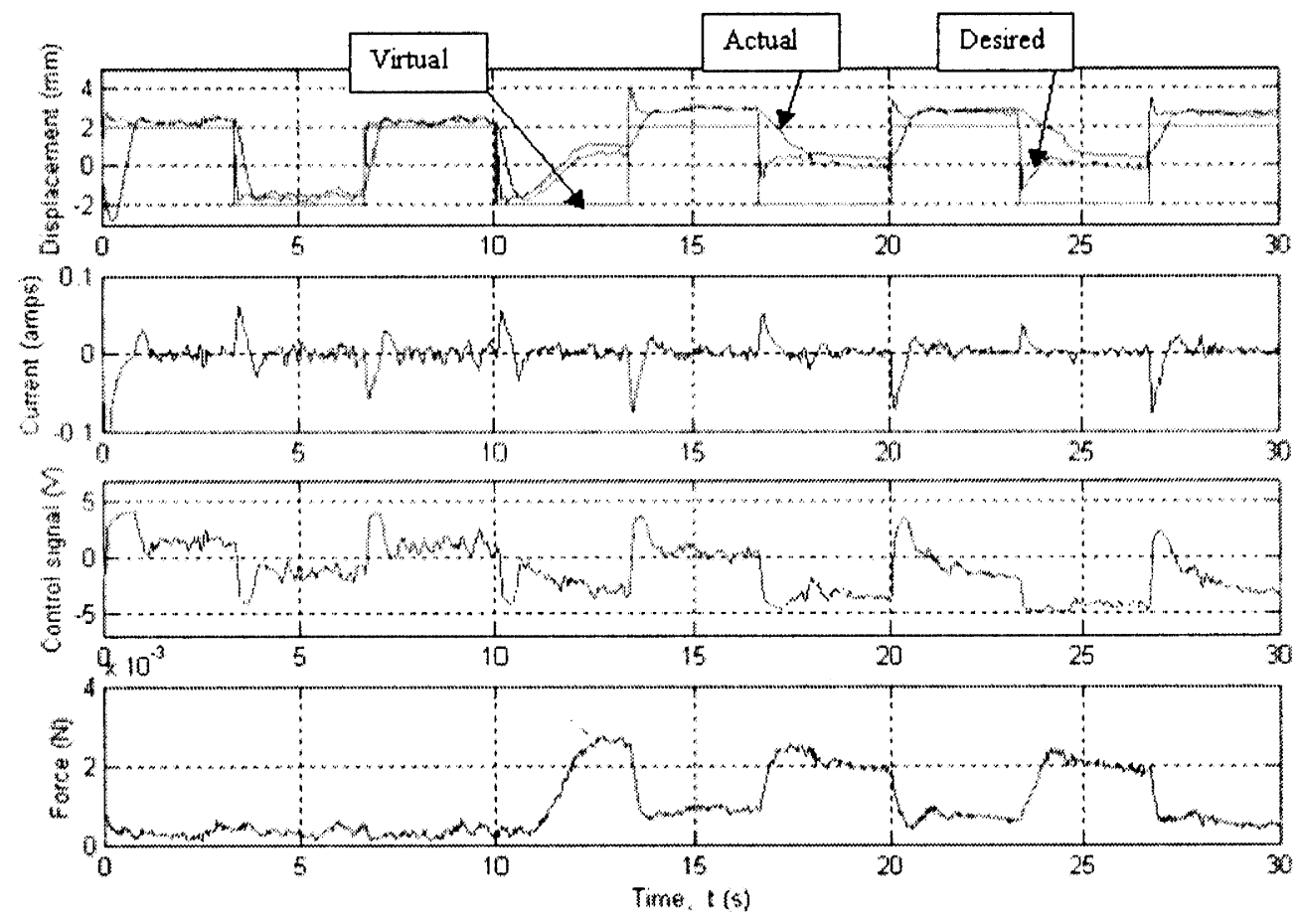

Fig. 12. IPMC impedance response $\left(K=1 \mathrm{~N} / \mathrm{m}, C=0.1 \mathrm{~N} / \mathrm{ms}^{-1}\right)$.
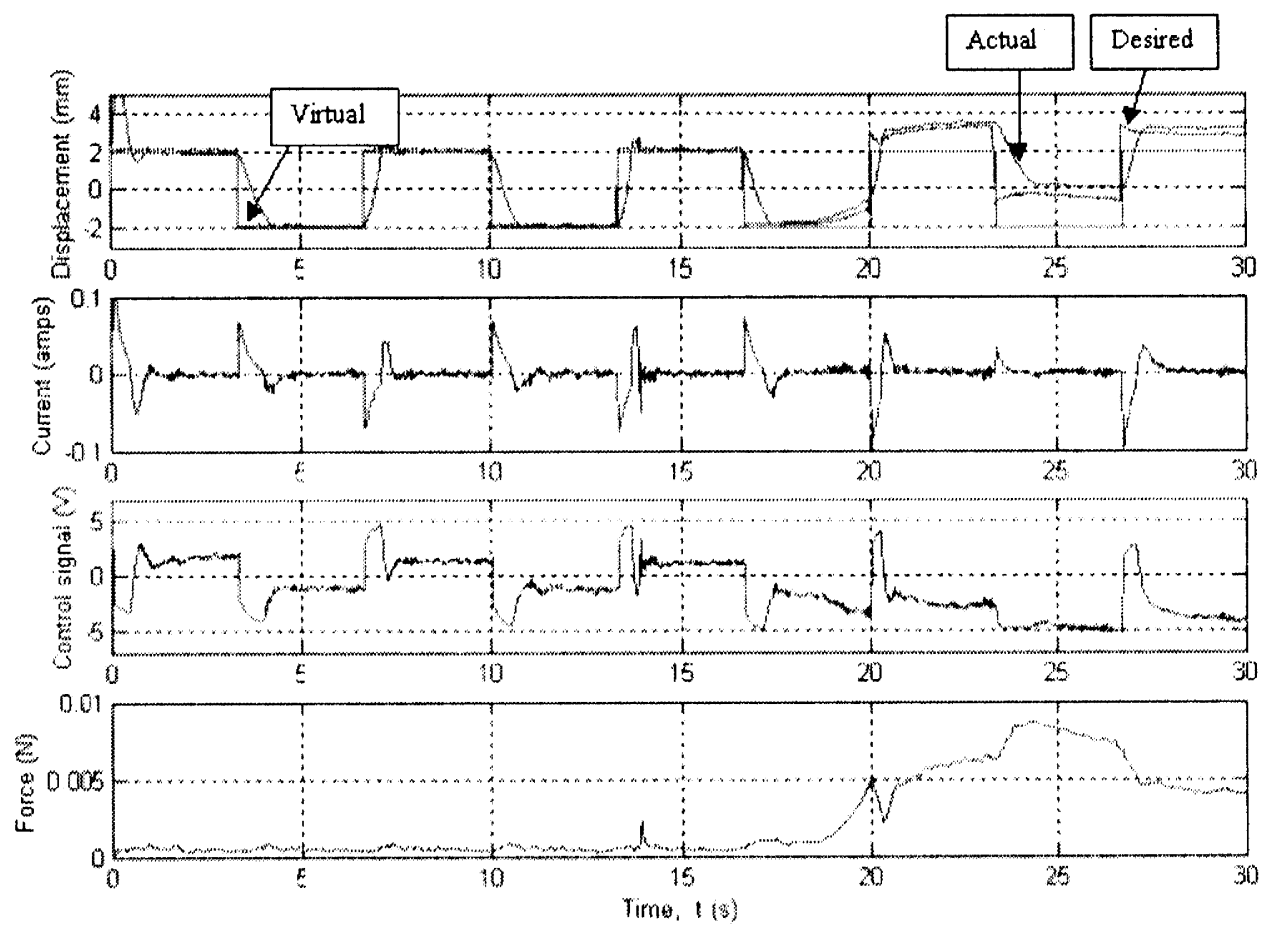

Fig. 13. IPMC impedance response $\left(K=5 \mathrm{~N} / \mathrm{m}, C=0.1 \mathrm{~N} / \mathrm{ms}^{-1}\right)$.

controller performance, the frequency of the applied external force and the impedance characteristics both need to be varied. Including a feedforward force element would improve the position controller's robustness to external forces [25].

Increasing the force output of these actuators through improved fabrication or multiple elements would increase the potential applications. For practical applications of interaction control, force sensing must be mounted on the actuator itself so that it is capable interacting autonomously in any environment. Further work will investigate improving the force output of the IPMC and improving the controller strategy.

\section{ACKNOWLEDGMENT}

The authors wish to acknowledge the support of the National Heart Research Fund, U.K. 


\section{REFERENCES}

[1] D. C. Caldwell, G. A. Medrano, and M. Goodwin, "Control of pneumatic muscle actuators," IEEE Control Syst., vol. 15, pp. 40-48, Nov. 1995.

[2] K. Uchino, "Piezoelectric ultrasonic motors: Overview," Smart Mater. Struct., vol. 7, pp. 273-285, 1998.

[3] S. G. Wax and R. R. Sands, "Electroactive polymer actuators and devices," in Proc. Conf. Smart Structures and Materials, vol. 3669, Newport Beach, CA, Mar. 1-2, 1999, pp. 2-9.

[4] M. Shahinpoor and K. J. Kim, "Ionic polymer-metal composites-I Fundamentals," Int. J. Smart Mater. Struct., vol. 10, pp. 819-833, 2001.

[5] D. Adolf, M. Shahinpoor, D. Segalman, and W. Witkowski, "Electrically controlled polymeric gel actuators," U.S. patent 5,250,167, Oct. 5, 1993.

[6] Ion-exchange polymer metal composites (IPMC) membranes. Worldwide electroactive polymer (EAP) webhub. NASA, Washington, DC. [Online]. Available: http://ndeaa.jpl.nasa.gov/nasa-nde/hommas/ eap/IPMC prepprocedure.htm.

[7] M. Shahinpoor and K. J. Kim, "Design, development, and testing of a multi-fingered heart compression/assist device equipped with IPMC artificial muscles," in Proc. SPIE Smart Structures and Materials: Electroactive Polymer Actuators and Devices, 2001, pp. 411-421.

[8] M. Shahinpoor and K. J. Kim, "The effect of surface-electrode resistance on the performance of ionic polymer-metal composite (IPMC) artificial muscles," in Proc. SPIE Smart Structures and Materials: Electroactive Polymer Actuators and Devices, vol. 3669, Newport Beach, CA, Mar. $1-2,1999$, pp. 308-319.

[9] K. Oguro and S. Sewa, "Polymer electrolyte with gold electrodes," in Proc. SPIE, Smart Materials and Structures, 1999, vol. 3669, pp. 64-71.

[10] S. Tadakoro, S. Yamagami, T. Takamori, and K. Oguro, "Modeling of Nafion-Pt composite actuators (ICPF) by ionic motion," in Proc. SPIE Conf. Electroactive Polymer Actuators and Devices, Newport Beach, CA, Mar. 2000, pp. 92-102.

[11] S. Nemat-Nasser and C. Thomas, "Ionic polymer-metal composite (IPMC)," in Electroactive Polymer (EAP) Actuators as Artificial Muscles-Reality, Potential and Challenges, Y. Bar-Cohen, Ed. Bellingham, WA: SPIE, 2001, pp. 139-191.

[12] J. H. Lee, J. D. Nam, H. R. Choi, H. M. Kim, J. W. Jeon, and H. K. Kim, "Water uptake and migration effect on IPMC (ion-exchange polymer metal composite) actuator," in Proc. SPIE Conf. Electroactive Polymer Actuators and Devices, Newport Beach, CA, Mar. 2001, pp. 84-93.

[13] K. Mallavarapu, K. M. Newbury, and D. J. Leo, "Feedback control of the bending response of ionic polymer-metal composite actuators," in Proc. SPIE Conf. Electroactive Polymer Actuators and Devices, vol. 5-8, Newport Beach, CA, Mar. 2001, pp. 301-310.

[14] S. Tadokoro, S. Yamagami, and T. Takamori, "An actuator model of ICPF for robotic applications on the basis of physicochemical hypotheses," in Proc. IEEE Int. Conf. Robotics and Automation, San Francisco, CA, Apr. 2000, pp. 1340-1346.

[15] Y. Bar-Cohen, Ed., Electroactive Polymer (EAP) Actuators as Artificial Muscles-Reality, Potential and Challenges. Bellingham, WA: SPIE, 2001.

[16] Y. Bar-Cohen, S. Leary, M. Shahinpoor, J. O. Harrison, and J. Smith, "Flexible low-mass device and mechanisms actuated by electroactive polymers," in Proc. SPIE Conf. Electroactive Polymer Actuators and Devices, Newport Beach, CA, Mar. 1-2, 1999, pp. 51-56.

[17] Y. Bar-Cohen, S. Sherrit, and S. Lih, "Characterization of the electromechanical properties of EAP materials," in Proc. SPIE Conf. Electroactive Polymer Actuators and Devices, Newport Beach, CA, Mar. 2001, pp. 319-327.

[18] T. Rashid and M. Shahinpoor, "Force optimization of ionic polymeric platinum composite artificial muscles by means of an orthogonal array manufacturing method," in Proc. SPIE Conf. Electroactive Polymer Actuators and Devices, Newport Beach, CA, Mar. 2000, pp. 289-298.

[19] M. Shahinpoor and K. J. Kim, "Fully dry solid state artificial muscles exhibiting giant electromechanical effect," in Proc. SPIE Conf. Electroactive Polymer Actuators and Devices, Newport Beach, CA, Mar. 2001, pp. $428-435$.

[20] D. E. Seborg, T. F. Edgar, and D. A. Mellichamp, Process Dynamics and Control. New York: Wiley, 1989.

[21] N. Hogan, "Impedance control: An approach to manipulation part I, II, III," J. Dyn. Syst., Meas. Control, vol. 107, no. 1, pp. 1-24, 1985.

[22] R. Richardson, "Control and actuation for robotic physiotherapy," Ph.D. dissertation, Dep. Mech. Eng., University of Leeds, Leeds, U.K., 2001.

[23] B. Heinrichs, N. Sepehri, and A. B. Thorton-Trump, "Position-based impedance control of an industrial hydraulic manipulator," IEEE Contr. Syst. Mag., vol. 17, pp. 46-52, Feb. 1997.
[24] Y. Bar-Cohen, C. Mavroidis, M. Bouzit, B. Dolgin, D. L. Harm, G. E. Kopchok, and R. White, "Virtual reality robotic telesurgery simulations using MEMICA haptic system," in Proc. SPIE Smart Structures and Materials, Electro-Active Polymer Actuators and Devices, Mar. 5-8, 2001, pp. 357-363.

[25] R. Richardson, M. D. Brown, and A. R. Plummer, "Pneumatic Impedance Control for Physiotherapy," in Proc. EUREL Int. Conf. Robotics., vol. 2, Mar. 2000.

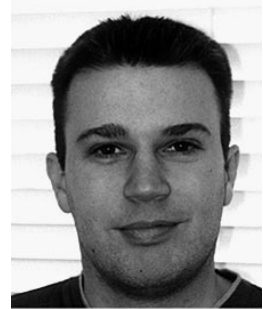

Robert C. Richardson received the B.Eng. degree in mechatronics and the Ph.D. degree (working in the area of actuation and control for a physiotherapy robot) from the University of Leeds, Leeds, U.K., in 1997 and 2001, respectively.

He was a Postdoctoral Research Fellow at the University of Leeds in 2001, working on the design, control, and actuation of a cardiac assist device. From 2002 to April 2003, he was a Teaching Fellow, responsible for the mechatronics undergraduate course and lectured modules in actuator systems and digital control. Since April 2003, he has been a Lecturer in Robotics, in the Department of Computer Science, University of Manchester, Manchester, U.K. as a part of the artificial intelligence group. His doctoral work involved the application of neurologically based controllers on a novel robot design to encourage recovery of the upper limb after stroke. His current research interests include rehabilitation robotics, robot and human interaction, modern actuator systems, and advanced control systems.

Martin C. Levesley received the B.Eng. degree in mechanical engineering from Brunel University, Brunel, U.K., in 1988, and the Ph.D. degree (working on efficient computation and experimental assessment of squeeze film damper response), from the University of Southampton, Southampton, U.K., in 1992.

He was a Senior Research Fellow at the University of Southampton, where his research continued to focus on the nonlinear modeling and control of motion in aero-engine rotor structures. In 1997, he joined the University of Leeds, Leeds, U.K., as a Lecturer, teaching dynamics and control, where his research interests broadened to include the analysis and control of motion in smart structures, smart self-sensing actuators, automotive systems, and robotic devices.

Dr. Levesley is a member of the Institute of Mechanical Engineers and a member of the Institute of Learning and Teaching in the U.K.

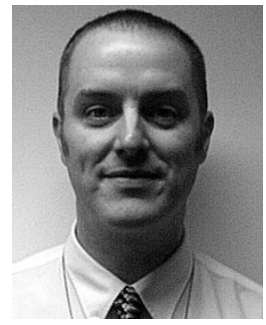

Michael D. Brown received the Ph.D degree (working in the area of adaptive control of power generation units) from Queen's University, Belfast, Ireland, in 1991

From 1991 to 1994, he was a Research Assistant studying the application of advanced control techniques and neural networks applied to power plants. In 1994, he became a Senior Applications Engineer with General Electric, Schenectady, NY, applying advanced signal processing and state-space control techniques to torsional vibration systems on power plant. From 1996 to 1998, he was a Senior Research Assistant at Queen's University, studying neural-fuzzy networks applied to chemical and power plants. In 1998, he became a Lecturer in control engineering at the University of Leeds, where he taught control, artificial intelligence and mechatronics, and progressed research in many fields from automotive control, vibration suppression, medical applications, and robotics. He is currently a Senior Engineer with Atkins Aviation and Defence Systems, Bristol, U.K., where he is developing advanced control techniques for submarine systems. $\mathrm{He}$ has published widely and has made over 60 contributions to international conferences, books, and journals.

Dr. Brown is a Chartered Engineer, and member of the Institution of Electric Engineers, U.K. 


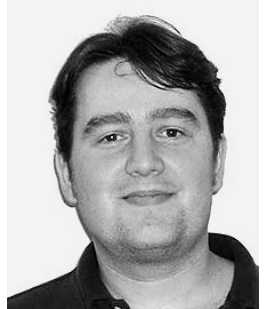

Jamie A. Hawkes received the B.Sc. degree in color and polymer chemistry from the University of Leeds, Leeds, U.K., in 1998, where he is working toward the $\mathrm{Ph} . \mathrm{D}$. degree, working on the synthesis and characterization of percarbamic acid, related compounds, and their precursors.

He is a Research Scientist in the Department of Color Chemistry, University of Leeds. The position was based on industrially funded projects for Elementis Chromium, Teeside, U.K., into the research and development of new nanocrystalline chromium pigments manufactured by novel routes, and Media Chemical Corporation, Trumbell, CT, to research and develop the photostability of dyes used in the manufacture of optical recording media. His doctoral work centers on the synthesis of substituted percarbamates, which have various end uses, such as bleach activators, dye decolorizers, and for antimicrobial or biochemical applications. His current research interests include bleaching and disinfection chemistry, dye chemistry, nanocrystalline pigment chemistry, and electroactive polymer chemistry.

His work on the novel compounds of interest has resulted in a patent (PCT WO 02/16538 A1).
Kevin Watterson, photograph and biography not available at the time of publication.

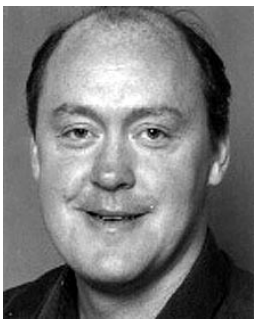

Peter G. Walker received the B.Sc. (Eng) degree in aeronautical engineering in 1983, and the Ph.D. degree in fluid mechanics in 1990, both from Imperial College of Science, Technology, and Medicine, London,U.K.

He joined the Technical University, Berlin, Germany, applying his doctoral thesis work on slow separated flows to the study of the flow through artificial heart valves and constructing a ten times enlarged heart valve and water tunnel. He then worked for five years at the Georgia Institute of Technology, Atlanta, in the area of general cardiovascular engineering before returning to take up his current appointment at the University of Leeds, Leeds, U.K., where he currently works on a wide range of biological flow problems using MRI, CFD, and experiments. 